\title{
EFFECT OF FINE PARTICLE PEENING USING HYDROXYAPATITE SHOT PARTICLES AND PLASMA SPRAYED HYDROXYAPATITE COATING ON FATIGUE PROPERTIES OF BETA TITANIUM ALLOY
}

\author{
YUKI NAKAMURA ${ }^{1}$, TAPPEI AOKI ${ }^{1}$, TOSHIHIRO SHIMIZU ${ }^{1}$, SHOICHI KIKUCHI ${ }^{2}$, \\ KOICHIRO NAMBU ${ }^{3} \&$ TOSHIKAZU AKAHORI ${ }^{4}$ \\ ${ }^{1}$ National Institute of Technology, Toyota College, Japan \\ ${ }^{2}$ Graduate School of Engineering, Kobe University, Japan \\ ${ }^{3}$ National Institute of Technology, Suzuka College, Japan \\ ${ }^{4}$ Faculty of Science and Technology, Meijo University, Japan
}

\begin{abstract}
Fine particle peening (FPP) and plasma spraying using hydroxyapatite particles were applied to a beta titanium alloy, Ti-22V-4Al, to form the hydroxyapatite (HAp) layer on the surface. As a result, HAp layer was formed on the specimen surface by the both treatments. The thicknesses were $5 \mu \mathrm{m}$ and $100 \mu \mathrm{m}$, respectively for FPP treated and plasma sprayed specimens. In the FPP treated specimen, Vickers hardness was increased by FPP compared with that of the untreated specimens, resulting in work-hardening. Rotary bending fatigue tests were carried out on both treated and untreated specimens. The FPP treated specimens exhibited higher fatigue strength than the untreated specimens. It is due to the increase in hardness and compressive residual stress by FPP. On the other hand, significant deteriorations of the fatigue strength for the plasma sprayed specimen was observed in comparison with the result for the untreated specimen. As a result of fracture surface observation in plasma sprayed specimen, the defect formed by blasting before the plasma spraying at interface between substrate and HAp layer was observed at crack initiation site. Thus, the defect plays a role as the crack starter in the case of plasma sprayed specimen.

Keywords: fatigue, fine particle peening, plasma spray, titanium alloy, hydroxyapatite.
\end{abstract}

\section{INTRODUCTION}

Titanium alloys have been used as implant components due to their high corrosion resistance, good biological compatibility and so on. In recent years, plasma and thermal spraying have been applied for titanium alloy to form the hydroxyapatite (HAp) layer on the surface and to improve osteo-conductivity [1]-[3]. However, Laonapakul et al. reported that delamination and spallation of the coating layer formed by plasma spraying occur under cyclic loading [3]. In this study, fine particle peening (FPP) treatment was applied for titanium alloy because the FPP treatment can improve the fatigue strength of metallic materials. In addition, the FPP treatment can create transferred layer consisted shot particle [4]-[6]. Thus, it is expected that the FPP treatment using hydroxyapatite shot particles can improve the fatigue strength and create HAp layer on the substrate.

The aim of this study is to form HAp transferred layer on the substrate by FPP and to compare the fatigue strength of FPP using HAp particles treated specimen and HAp coated specimen by plasma spraying. Rotating bending fatigue tests were carried out for FPP treated specimens. Tests were also conducted on untreated specimens and hydroxyapatite coated specimens by plasma spraying for comparison. Fracture surface of all the failed specimens were examined in a scanning electron microscope (SEM). The effects of FPP and plasma spray on fracture mechanisms are also discussed in the light of fractography. 


\section{EXPERIMENTAL PROCEDURE}

\subsection{Material and specimen}

The material used is the $\beta$-type titanium alloy, Ti-22V-4Al, whose chemical composition (wt.\%) is as follows; Al: 4.15, V: 21.17, Fe: 0.15, C: 0.013, O: 0.14, N: 0.012, H: 0.0124, Ti: bal. This material was water-quenched at $1023 \mathrm{~K}$ for $1 \mathrm{~h}$, followed by tempered at $823 \mathrm{~K}$ for $4 \mathrm{~h}$. The mechanical properties of Ti-22V-4Al after heat treatment are listed in Table 1. After the heat treatment, the hourglass-shape fatigue specimens were machined as shown in Fig. 1 and the specimen surface was polished by emery paper with the grade of \#4000. After polishing, FPP was performed on the polished specimen. Before the fatigue test, the FPP treated specimens were put inside an ultrasonic bath using acetone to remove the free HAp particles on the specimen. In the case of plasma sprayed specimen, alumina grit blasting was conducted on the polished specimen, and then plasma sprayed hydroxyapatite coating was performed.

\subsection{Characterization of FPP treated and plasma sprayed specimen}

Surface and cross-section near the surface of FPP and plasma sprayed specimen was observed using scanning electron microscope (SEM). The analysis of elements at the FPP treated surface was performed by energy dispersive X-ray spectroscopy (EDX) to confirm the HAp transferred layer formed by FPP. The hardness of untreated, FPP treated and plasma sprayed specimen surfaces were measured using a micro-Vickers hardness tester at a load of $9.8 \mathrm{~N}$. The residual stress was also measured at the surface of untreated, FPP treated and alumina grit blasted specimens by X-ray diffraction (XRD).

\subsection{Experimental methods}

Fatigue tests were performed using cantilever-type rotary bending fatigue testing machines operating at a frequency of $53 \mathrm{~Hz}$ in laboratory air. The machine has two spindles driven by an electric motor via a flat belt, and each spindle has specimen grips at both ends [7]. Thus, it can perform fatigue tests of four specimens simultaneously. Eccentricity of the specimens

Table 1: Mechanical properties.

\begin{tabular}{|c|c|c|c|c|}
\hline $\begin{array}{c}\text { Young's } \\
\text { modulus } \\
E[\mathrm{GPa}]\end{array}$ & $\begin{array}{c}\text { Yield } \\
\text { stress } \\
\sigma_{\mathrm{Y}}[\mathrm{MPa}]\end{array}$ & $\begin{array}{c}\text { Tensile } \\
\text { strength } \\
\sigma_{\mathrm{B}}[\mathrm{MPa}]\end{array}$ & $\begin{array}{c}\text { Elongation } \\
\delta[\%]\end{array}$ & $\begin{array}{c}\text { Resuction of } \\
\text { area } \\
\varphi[\%]\end{array}$ \\
\hline 97 & 1154 & 1235 & 9.3 & 21.9 \\
\hline
\end{tabular}



Figure 1: Specimen configuration. 
mounted the specimen grips was kept within $\pm 20 \mu \mathrm{m}$ at the tip of each specimen. The rotating speed of the spindle is $3150 \mathrm{rpm}$. All the fatigue tests were conducted at room temperature and in laboratory environment. After fatigue tests, fracture surfaces of failed specimens were examined in a scanning electron microscope (SEM).

\section{RESULTS AND DISCUSSION}

\subsection{Characterization of FPP treated and plasma sprayed specimens.}

Fig. 2 shows the surface of untreated, FPP treated and plasma sprayed specimen. As shown in Fig. 2(a), a smooth surface was formed by polishing for the untreated specimen. On the other hand, in FPP treated and plasma sprayed specimen, the rough surface was formed by plastic deformation due to collision of HAp particles with the specimen surface.

The analysis of elements at FPP treated specimen surface was performed by EDS. Fig. 3 shows EDX maps of the FPP treated specimen surface. As seen in the figure, calcium $(\mathrm{Ca})$, oxygen $(\mathrm{O})$ and phosphorus $(\mathrm{P})$ elements which was contained in HAp particles were


Figure 2: $\quad$ SEM images of surfaces. (a) Untreated specimen; (b) FPP treated specimen; (c) Plasma sprayed specimen.

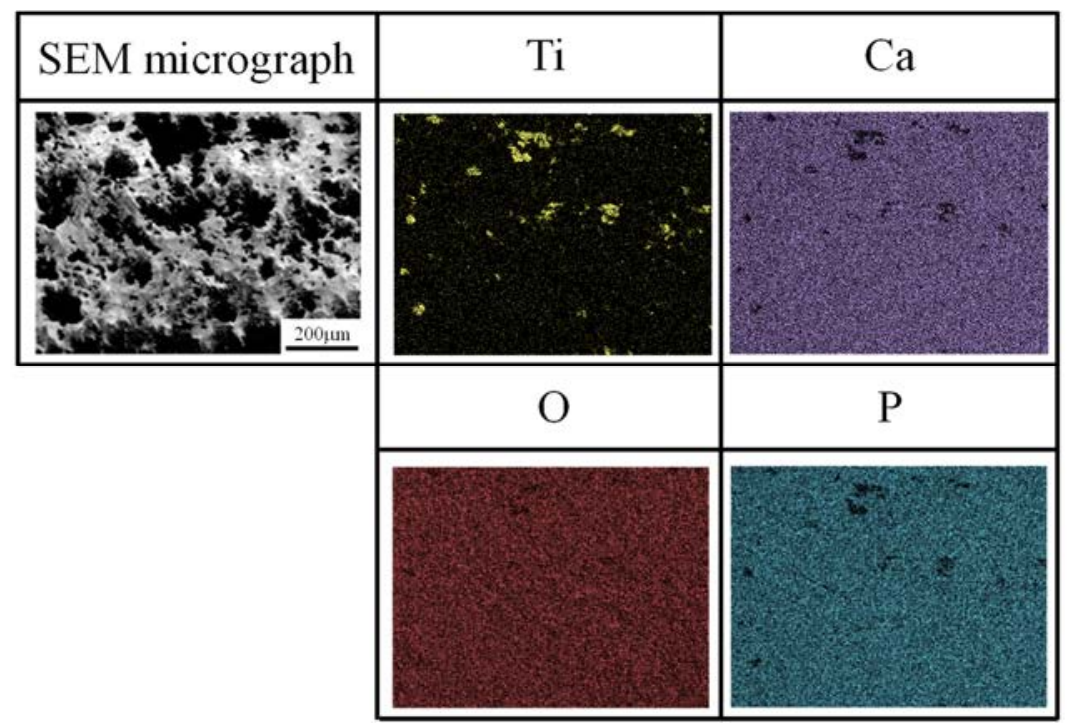

Figure 3: EDX maps for surface of FPP treated specimen. 
detected at the whole surface of FPP treated specimen which suggests that the HAp transferred layer was formed on the specimen surface.

Fig. 4 shows the cross-sections of FPP treated and plasma sprayed specimens. As seen in the Fig. 4(a), HAp layer was formed on the substrate by FPP. Thus, FPP using HAp particles can form HAp transferred layer on the specimen surface, and its's about $5 \mu \mathrm{m}$ in thickness. In the case of plasma sprayed specimen, thick HAp layer was formed on the substrate (Fig. 4(b)). The thickness is about $100 \mu \mathrm{m}$. Furthermore, the interface between HAp layer formed by plasma spray and substrate was very rough because alumina grit blasting was performed before the plasma spray.

Fig. 5 shows the results of Vickers hardness measurement for each specimen. In the case of FPP treated and plasma sprayed specimen, the hardness of substrate beneath the HAp layer was measured. It was found that FPP increased the hardness of substrate. The hardness of plasma sprayed substrate was also improved due to alumina grit blasting before plasma spraying.

Fig. 6 shows the residual stress generated on the surfaces of the untreated, FPP treated and alumina grit blasted specimen. Compressive residual stress was increased at the surface of the FPP treated and alumina grit blasted specimens.
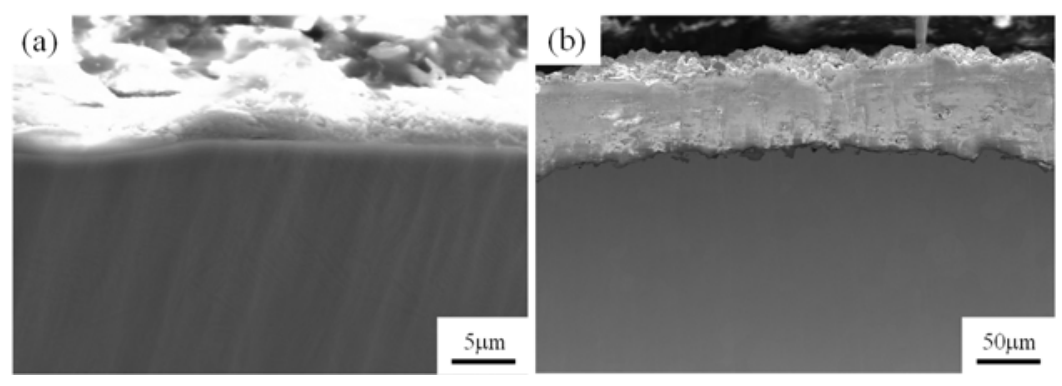

Figure 4: SEM images of cross-sections. (a) FPP treated specimen; (b) Plasma sprayed specimen.

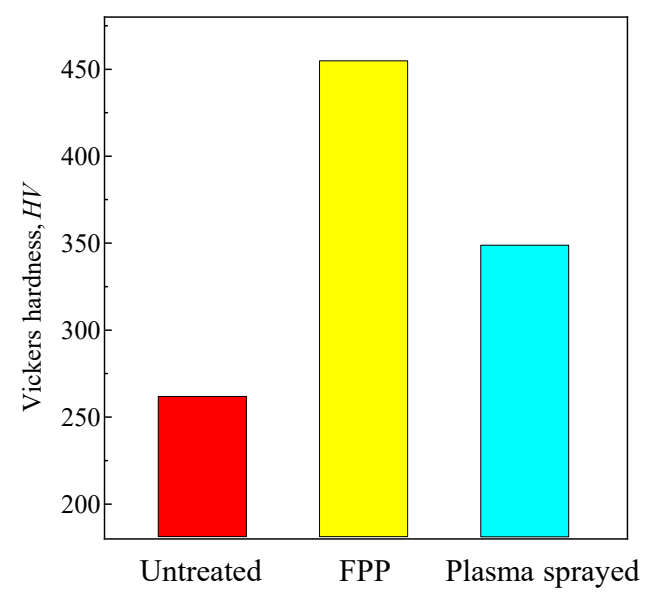

Figure 5: Vickers hardness of untreated, FPP treated and plasma sprayed specimens. 


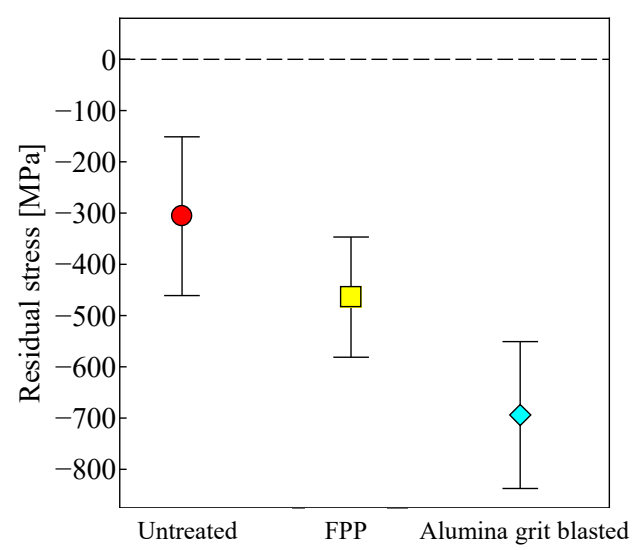

Figure 6: Residual stresses of untreated, FPP treated and alumina grit blasted specimens.

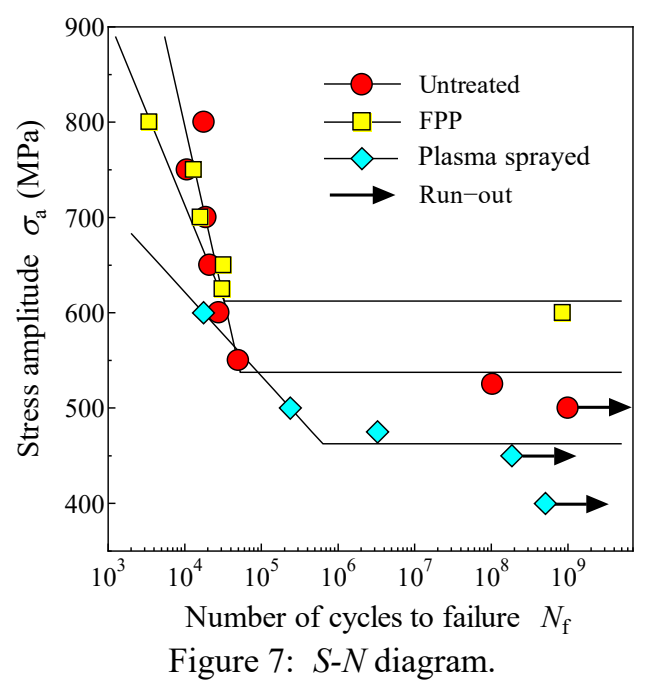

\subsection{Fatigue properties}

Fig. 7 shows the $S-N$ curves for each specimen. Data points with arrow indicate the run-out specimen. $S-N$ curves of all types of specimen indicate fatigue limit. Based on this result, $S$ - $N$ curves were determined by accepting the $S$ - $N$ curve model with fatigue limit in the JSMS standard [8]. The fatigue limit of the untreated specimen was $538 \mathrm{MPa}$, while $613 \mathrm{MPa}$ and $463 \mathrm{MPa}$ for the FPP treated and plasma sprayed specimens, respectively. The FPP treated specimen exhibits the highest fatigue limit of all due to the significant increasing of hardness. In addition, the subsurface fracture was seen in the FPP treated specimen. Fig. 8 shows the SEM image of subsurface fracture surface. No defect (inclusion or defect) was found at crack initiation site. In the plasma sprayed specimen, it is clear that a significant deterioration of the fatigue strength was observed, compared to the untreated and the FPP treated specimens. Fig. 9 shows the SEM image of crack initiation site of the plasma sprayed specimen. In this case, a defect formed by alumina grit blasting was found at the crack initiation site, suggesting fatigue crack initiation from the defect. 


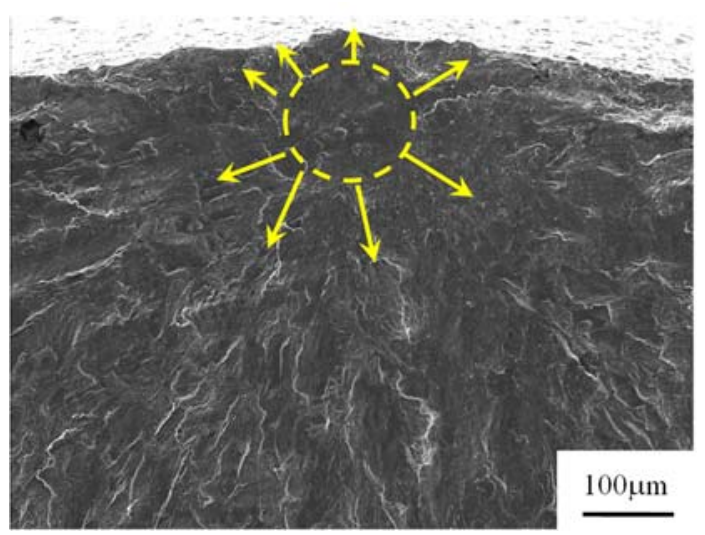

Figure 8: SEM image showing the FPP treated specimen fracture surface $\left(\sigma_{\mathrm{a}}=600 \mathrm{MPa}\right.$, $\left.N_{\mathrm{f}}=8.5 \times 10^{8}\right)$.

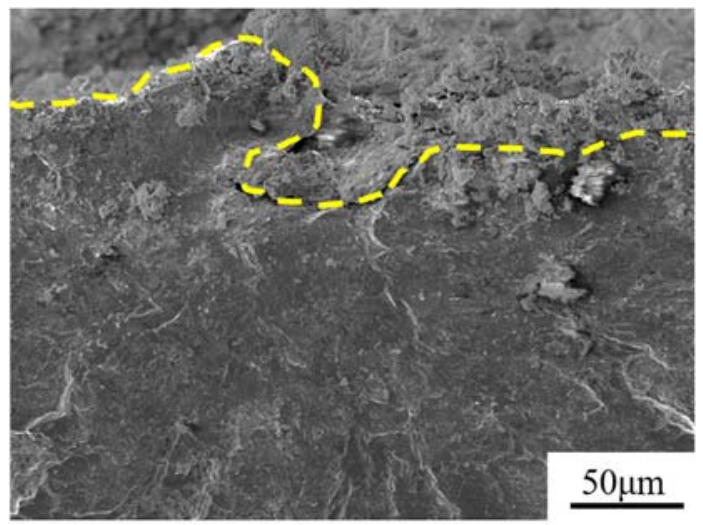

Figure 9: $\quad$ SEM image showing the plasma sprayed specimen fracture surface $\left(\sigma_{\mathrm{a}}=475\right.$ $\left.\mathrm{MPa}, N_{\mathrm{f}}=3.3 \times 10^{6}\right)$.

\section{CONCLUSIONS}

In this study, fine particle peening (FPP) using hydroxyapatite (HAp) shot particles and plasma sprayed hydroxyapatite coating were performed to a beta titanium alloy, Ti-22V-4Al. Rotary bending fatigue tests were conducted using the untreated, FPP treated and plasma sprayed specimens to investigate the effect of surface treatments on the fatigue properties. The results obtained are as follows:

1. FPP using HAp particles can form the HAp transferred layer on the surface of Ti22-4Al.

2. The hardness and the compressive residual stress were increased by FPP and plasma spray.

3. In the FPP treated specimen, the fatigue limit was improved due to the increase in hardness and compressive residual stress. On the other hand, in plasma sprayed specimen, the fatigue limit was deteriorated significantly. This is because the defect formed by alumina grit blasting played a role as the crack starter during the fatigue process. 


\section{ACKNOWLEDGEMENTS}

The authors would like to thank The Naito Science \& Engineering Foundation, the Inamori Foundation for the support and JSPS KAKENHI Grant Number 16K17986. FPP treatment was conducted on the basis of the Japanese Patent (No. 3314070) applied by FUJI KIHAN Co., Ltd and Aichi Center for Industry and Science Technology.

\section{REFERENCES}

[1] Bhadang, K.A. \& Gross, K.A., Influence of Fluorapatite on the Properties of Thermally Sprayed Hydroxyapatite Coatings. Biomaterials, 25(20), pp. 4935-4945, 2004.

[2] Yang, Y. \& Chang, E., Measurements of Residual Stresses in Plasma-sprayed Hydroxyapatite Coatings on Titanium Alloy. Surface \& Coatings Technology, 190(1), pp. 122-131, 2005.

[3] Laonapakul, T., Nimkerdphol, A.R., Otsuka, Y. \& Mutoh, Y., Failure Behavior of Plasma-sprayed HAp Coating on Commercially Pure Titanium Substrate in Simulated Body Fluid (SBF) under Bending Load. Journal of the Mechanical Behavior of Biomedical Materials, 15, pp. 153-166, 2012.

[4] Kikuchi, S., Yoshida, S., Nakamura, Y., Nambu, K. \& Akahori, T., Characterization of the hydroxyapatite layer formed by fine hydroxyapatite particle peening and its effect on the fatigue properties of commercially pure titanium under four-point bending. Surface \& Coatings technology, 288(25), pp. 196-202, 2016.

[5] Kameyama, Y.\& Komotori, J., Effect of Micro Ploughing During Fine Particle Peening Process on the Microstructure of Metallic Materials. Journal of Materials Processing Technology, 209(20), pp. 6146-6155, 2009.

[6] Kameyama, Y. \& Komotori, J., Tribological Properties of Structural Steel Modified by Fine Particle Bombadment (FPB) and Diamond-like Carbon Hybrid Surface Treatment. Wear, 263, pp. 1354-1363, 2007.

[7] Sakai, T., Furusawa, T., Takizawa, R., Oguma, N., Hohjo H. \& Ikuno, H., Development of Multi-Type High Frequency Fatigue Testing Machines in Rotating Bending and Axial Loading. Proceedings of Hael Mughrabi Honorary symposium, $137^{\text {th }}$ annual meeting and exhibition, pp. 241-246, 2008.

[8] Sakai, T \& Sugeta, A., Publication of the Second Edition of "Standard Evaluation Method of Fatigue Reliability for Metallic Materials" [Standard Regression Method of $S-N$ Curves]. Journal of the Society of Materials Science, Japan, 54, pp. 37-43, 2005. 